\title{
Evaluación in vitro de la capacidad bacteriana para remover plomo en aguas residuales sintéticas
}

Lenin Javier Ramírez Cando, Santiago Paúl Guerra Guevara, Gabriela Alejandra Reinoso Molina Ponente (s): Gabriela Alejandra Reinoso Molina, Santiago Paúl Guerra Guevara

E-mail: gb_aj02@hotmail.com

Institución: Universidad Politécnica Salesiana País: Ecuador

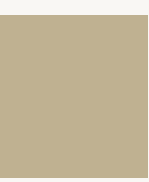

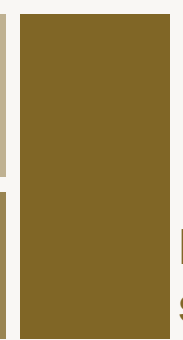

In vitro evaluation of the
synthetic wastewater

\section{Resumen} DÍA MUNDIAL DEL MEDIO AMBIENTE - ECUADOR 2016 Universidad Central del Ecuador $14,15,16$ y 17 de junio de 2016

Con la finalidad de mitigar los impactos ambientales ocasionados por diferentes actividades industriales relacionadas con el sector minero, petroquímico, metalúrgico, entre otros, se ha realizado una caracterización in vitro de 152 microorganismos entre cepas y consorcios bacterianos. En la fase de aislamiento y bioestimulación las bacterias fueron sometidas a selección en medio de cultivo modificado, en el cual se adicionó concentraciones de 20 y 100 ppm de Pb, obteniendo finalmente cinco cepas que mostraron ser resistentes y/o tolerantes al Pb. La determinación de la capacidad bacteriana de remoción de Pb se experimentó a dos condiciones: incubación a temperatura controlada de $25^{\circ} \mathrm{C}$ e incubación a temperatura ambiente (entre $5^{\circ} \mathrm{C}$ y $23^{\circ} \mathrm{C}$ para la zona sur de Quito en los meses de estudio). La caracterización bioquímica se realizó mediante el Kit Microgen GN-ID A+B, identificándose los siguientes géneros: Acinetobacter, Pseudomona, Aeromona y las especies: Aeromona hydrophila y Photobacterium damselae, la misma que obtuvo el 99,8\% de certeza. En la elaboración de las curvas de cinética de crecimiento bacteriano y remoción de Pb, se utilizó técnicas de turbidimetría y absorción atómica, en donde Aeromona hydrophila presentó mayor facilidad de crecimiento a 20 ppm en incubación a temperatura ambiente, mientras que Pseudomona sp registró un porcentaje de remoción total de Pb del 96,30\% a 100 ppm e incubación a temperatura ambiente. La investigación pretende servir de guía para futuros estudios de manera que pueda ser empleada como una alternativa de remediación más eficiente y económica en relación a las tecnologías de remediación convencionales.

\section{Palabras Clave: agua residual; in vitro; plomo; bacteriana}

\section{Abstract}

With the purpose of mitigating the environmental impacts caused by different industrial activities related to the mining, petrochemical, metallurgical sector, among others, an in vitro characterization of 152 microorganisms has been carried out between strains and bacterial consortia. In the isolation and biostimulation phase the bacteria were subjected to selection in a modified culture medium, in which concentrations of 20 and 100 ppm of Pb were added, finally obtaining five strains that showed to be resistant and / or tolerant to Pb. The determination of the bacterial capacity of removal of $P b$ was experienced under two conditions: incubation at a controlled temperature of $25^{\circ} \mathrm{C}$ and incubation at room temperature (between $5^{\circ} \mathrm{C}$ and $23^{\circ} \mathrm{C}$ for the southern zone of Quito in the months of study). The biochemical characterization was carried out through the Kit Microgen GN-ID $A+B$, identifying the following genera: Acinetobacter, Pseudomona, Aeromona and the species: Aeromona hydrophila and Photobacterium damselae, the same one that obtained $99.8 \%$ certainty. In the development of the curves of kinetics of bacterial growth and removal of $\mathrm{Pb}$, turbidimetry and atomic absorption techniques were used, where Aeromona hydrophila showed greater ease of growth at 20 ppm in incubation at room temperature, while that Pseudomona sp recorded a percentage of total Pb removal of $96.30 \%$ at 100 ppm and incubation at temperature ambient. The research aims to serve as a guide for future studies so that it can be used as a more efficient and economical remediation alternative in relation to conventional remediation technologies.

Keywords: residual water; in vitro; lead; bacterial 


\section{Introducción}

Los adelantos industriales y tecnológicos de las últimas décadas han ocasionado graves problemas de contaminación ambiental. Según Eróstegui (2009) las principales industrias responsables de la emisión de metales pesados al ambiente son las industrias minera, petroquímica y metalúrgica.

El suelo y el agua se ven afectados principalmente por la industria minera debido a las altas concentraciones de metales como arsénico, cadmio, cobre, cromo, hierro, plomo y selenio, generados a lo largo de sus actividades (Turcios \& García, 2010). La utilización de bacterias para remediar estos ambientes contaminados y la búsqueda de una mejora continua en cada uno de los procesos mineros, son alternativas que reducirían de manera significativa los impactos ocasionados por esta industria.

Por otra parte García, Castells, \& Gaya (2012) señalan que la industria petroquímica ha sido considerada como potencialmente peligrosa, debido a los graves riesgos asociados a sus actividades, accidentes de barcos petroleros de gran tonelaje y a los vertidos ocasionados por la limpieza y mantenimiento de sentinas. Entre las consecuencias directas podemos mencionar los daños a la vida marina y a los ecosistemas terrestres, los mismos que repercuten de manera negativa en las actividades económicas de las zonas afectadas (Greenpeace, 2008). En algunos casos los daños ocasionados al ambiente se pueden considerar irreversibles, es decir, cuando el daño cubre grandes extensiones de terreno y la remediación es muy complicada o costosa y afecta de manera considerable a las especies animales y vegetales, llegando inclusive a poner en riesgo su existencia.

Como lo mencionan Bustos, Garzón, \& Tamayo (2015) el sector metalúrgico tiene cuatro tipos de contaminación ambiental: emisiones atmosféricas, residuos sólidos, emisiones líquidas y ruidos. La generación de residuos sólidos para Ambuludi \& Hoyos (2013) es considerada como la que mayor contaminación produce, debido a que en los diferentes procesos metalúrgicos se generan residuos de metales pesados como plomo, níquel, cobre, zinc, mercurio, arsénico y cadmio, los cuales pueden acumularse en los organismos de seres vivos.

Para mitigar los impactos ambientales ocasionados por las diferentes actividades industriales se han empleado varias técnicas de biorremediación como: la fitorremediación, que utiliza plantas para concentrar, transferir 0 destruir contaminantes (Volke \& Velasco, 2002), tal es el caso de Eichhornia crassipes, una planta acuática perenne ampliamente estudiada para ser empleada en fitorremediación ex situ, principalmente como herramienta para la limpieza efectiva de efluentes contaminados con metales pesados, plaguicidas y colorantes vertidos por varias industrias (Guevara \& Ramírez, 2015); otra de las técnicas empleadas para recuperar y limpiar estos ambientes contaminados es la remediación con bacterias, la misma que según Sánchez \& Rodríguez (2010) es considerada como una tecnología que utiliza el potencial metabólico de los microorganismos, específicamente su capacidad para degradar total 0 parcialmente una amplia gama de compuestos.

Algunos géneros de bacterias como Pseudomona, Xanthomonas, Ferroxidans, Ralstonia, Acidobacillus presentan capacidad como agentes biorremediantes, ya que éstas son capaces de extraer metales de sustratos sólidos, ser utilizadas como bioabsorbentes para la recuperación de metales y para el tratamiento de efluentes industriales (Suárez \& Reyes, 2002; Torres, 2003). La capacidad del género Pseudomona para degradar compuestos tóxicos según Torres (2003) depende del tiempo de contacto con el compuesto, las condiciones ambientales y su versatilidad fisiológica, siendo considerado como uno de los géneros más eficientes al momento de degradar contaminantes.

Las características que debe tener un microorganismo para ser considerado útil a nivel industrial son producir la sustancia de interés, estar disponible en cultivo puro, debe ser genéticamente estable, crecer en cultivos a gran escala, crecer rápidamente y producir el producto deseado en cortos periodos de tiempo, crecer en un medio de cultivo barato y disponible en grandes cantidades y no debe ser patógeno (Morales, 2012).

Existen múltiples aplicaciones industriales de las bacterias, como explican Castillo \& Barragán (2011) en la industria alimentaria algunas bacterias lácticas: Lactobacillus, Bifidobacterium, Pediococcus, Estreptococcus y Leuconostoc, pueden preservar y conservar las características organolépticas de los alimentos (Ramírez, Ulloa, Velázquez, Ulloa, \& Arce, 2011); en el caso de la industria farmacéutica los géneros: Streptomyces, Bacillus, Streptomyces, se puede incorporar a principios activos para originar nuevos medicamentos y antibióticos; en la industria de plásticos y papel se desea mejorar los productos, procesos y crear nuevas tecnologías amigables con el ambiente, por ejemplo Alcaligenes puede ser utilizada en la fabricación de bioplásticos; en la depuración de aguas residuales, en fangos activados son de gran utilidad las bacterias aerobias y finalmente en la biodegradación de xenobióticos las Pseudomonas son empleadas en la biodegradación de hidrocarburos y algunos metales pesados.

Una de las principales ventajas de la biorremediación como lo explican Sánchez \& Rodríguez (2010, pág. 12) se debe a que "esta tecnología utiliza el potencial metabólico de los microorganismos (fundamentalmente bacterias, pero también hongos y levaduras) para transformar contaminantes orgánicos en compuestos más simples y poco 0 nada contaminantes", adicionalmente González (2011) explica que la biorremediación también se puede utilizar para limpiar terrenos o aguas contaminadas con el uso de recursos económicos más bajos que otras técnicas convencionales. 
Como lo describe Safont (2012, pág. 7) otra de las ventajas de la biorremediación "es que es una tecnología poco intrusiva en el medio ambiente y generalmente no requiere componentes estructurales 0 mecánicos dignos de destacar".

"Los costos de biorremediación se encuentran entre 100 y 250 USD/m3, mientras que las tecnologías convencionales, como la incineración o rellenos sanitarios seguros pueden costar entre 250 y 1000 USD/m3" (Volke, 2012). Debido a esto la biorremediación se convierte en una alternativa muy viable y eficaz, por cuanto algunos microorganismos son capaces de tolerar y degradar compuestos de gran toxicidad a bajo costo.

\section{Materiales y métodos}

\section{Aislamiento y bioestimulación de bacterias}

Las muestras de agua residual fueron obtenidas de los diferentes efluentes de las industrias mineras, petroquímicas y metalúrgicas ubicadas en la región costa del Ecuador utilizando el método de muestreo aleatorio simple.

Para la bioestimulación se preparó medio de cultivo Agar Cetrimida DIFCOTM y se añadió $15 \mathrm{ml}$ de estándar de plomo de 1000 ppm equivalente a 20 ppm de plomo; posteriormente se inoculó 0,1 y $1 \mathrm{ml}$ de cada muestra en cajas petri previamente esterilizadas utilizando la técnica de siembra por inmersión y se incubaron por 48 horas a $25^{\circ} \mathrm{C}$ en incubadora Memmert SNB-400. A continuación se revisó y contabilizó las unidades formadoras de colonias (UFC) y se separó las colonias que presentaron diferentes morfologías, el aislamiento bacteriano se realizó mediante siembra repetitiva de colonias obtenidas con la técnica de agotamiento por estrías en placa de agar Cetrimida hasta llegar a obtener cajas con morfología uniforme.

\section{Caracterización bioquímica de bacterias}

El inóculo se preparó con el kit de caracterización bioquímica The Microgen GN-ID A + B System y se procedió según el manual del usuario.

\section{Selección de las cepas bacterianas resistentes a altas concentraciones de Plomo}

Para la selección de las cepas bacterianas se preparó medio de cultivo basado en el procedimiento establecido por Ramírez \& Coba (2012), como se detalla a continuación: 1 $\mathrm{g}$ de sulfato de sodio, $4 \mathrm{~g}$ de extracto de levadura, $5 \mathrm{~g}$ de sacarosa y 20 ppm de Pb aforados a 1 litro y se dispensó $300 \mathrm{ml}$ en cada matraz. El mismo procedimiento se lo realizó para la concentración de 100 ppm de Pb. Posteriormente se inoculó cada cepa bacteriana en el medio de cultivo y se incubó a $22{ }^{\circ} \mathrm{C}$ durante 72 horas.

\section{Análisis de la cinética de crecimiento bacteriano}

Se consideró como factores ambientales: viabilidad de crecimiento, temperatura, $\mathrm{pH}$ y como factor independiente la concentración de plomo. El inóculo se preparó con las bacterias aisladas, presentes en las muestras obtenidas en los efluentes de agua residual; sin embargo, el experimento se realizó con aquellas bacterias que lograron adaptarse a concentraciones de 20 y 100 ppm de Pb.

Se preparó el medio de cultivo líquido establecido por Ramírez \& Coba (2012), se añadió $15 \mathrm{ml}$ de estándar de plomo de 1000 ppm que equivalen a 20 ppm de Pb, para la segunda concentración se añadió $0,184 \mathrm{~g}$ de acetato de plomo que equivalen a 100 ppm de $\mathrm{Pb}$. A continuación, se dispensó $300 \mathrm{ml}$ de medio líquido en cada uno de los matraces con las cepas seleccionadas anteriormente.

\section{Elaboración de la curva de calibración}

Para la elaboración de la curva de calibración se preparó los estándares McFarland del modo que se describe en la Tabla 1.

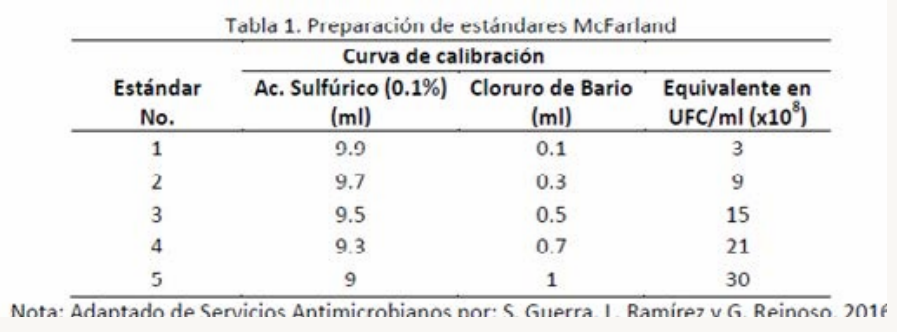

Una vez preparados los estándares McFarland se tomaron las lecturas por triplicado de cada uno de los estándares y el blanco (agua destilada) con el turbidímetro Lovibond Water Testing TB 210 IR. Con esos datos se pudo obtener la ecuación que define el crecimiento bacteriano.

\section{Determinación de la curva de crecimiento}

Para determinar la curva de crecimiento se inoculó las cepas bacterianas en los matraces, homogenizándolas con una agitación moderada, para luego ser incubados en dos bloques, incubación a temperatura ambiente e incubación a temperatura controlada $\left(25^{\circ} \mathrm{C}\right)$, la primera medición se realizó luego de 4 horas de iniciada la incubación. Para realizar la medición se tomó una alícuota del medio de cultivo previamente agitado, y se tomaron las lecturas con el turbidímetro ajustado a $860 \mathrm{~nm}$.

Luego se midió consecutivamente la absorbancia de cada medio de cultivo inoculado en intervalos de 2 horas, hasta obtener lecturas constantes de absorbancia en los medios de cultivo.

\section{Determinación de la curva de remoción}

Para determinar la curva de remoción se preparó medio de cultivo a 20 ppm y a 100 ppm de Pb como se indica 
en el apartado 2.4; se sembró las cepas seleccionadas con anterioridad en matraces por duplicado, y se tomaron mediciones de $\mathrm{pH}$, temperatura y turbidez, cada dos horas, durante 4 días.

\section{Tratamiento estadístico de datos}

En el análisis de los resultados se utilizó diferentes pruebas estadísticas, entre ellas, el coeficiente de correlación de Pearson, que permitió determinar el grado de relación existente entre la linealización de la curva de crecimiento y las variables: tiempo, temperatura interna del cultivo (TEMP), pH y concentraciones de plomo.

Para conocer si los datos siguieron una distribución normal (datos de pH y temperatura interna del cultivo) se utilizó la prueba de Normalidad de Shapiro Wilk; si el resultado de esta prueba era normal, se aplicó la prueba estadística t-Student (varianzas iguales), la misma que nos permitió determinar si existe 0 no una diferencia en promedio de Ios datos analizados; y si el resultado no era normal, se aplicó la prueba U de Mann Whitney para comprobar si el comportamiento de las dos variables era diferente.

\section{Diagrama de flujo}

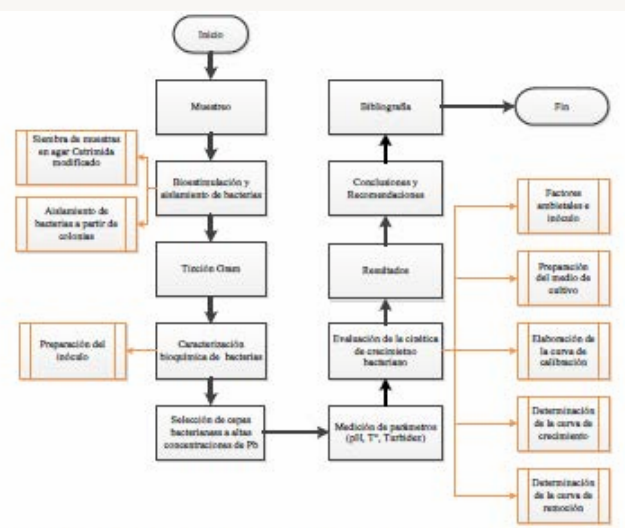

Figura 1. Flahorado nor: S. Guerra. I. Ramírez v G. Reinoso. 201

\section{Resultados y discusión}

En el presente estudio, se analizó un total de 152 microorganismos entre cepas y consorcios bacterianos; como se indica en la Tabla 2, seis cepas resultaron resistentes y/o tolerantes a las concentraciones de Pb ensayadas y seis cepas resultaron sensibles, es decir, que la proporción de bacterias aisladas resistentes es de un 50\% y un 3.9\% de bacterias resistentes con respecto al total de las colonias analizadas. Para realizar el experimento se seleccionaron cuatro cepas (2.63\%) en función de su desempeño y de las características macro y microscópicas.

Tabla 2. Aislamiento y bioestimulación de bacterias

\begin{tabular}{lccccc}
\hline \multicolumn{1}{c}{ Microorganismos } & Cantidad & Resistentes & Sensibles & Proporción & Resis. Total \\
\hline Bacterias aisladas & 12 & 6 & 6 & $50,0 \%$ & $3,9 \%$ \\
Consorcios & 140 & 37 & 103 & $26,4 \%$ & $24,3 \%$ \\
\hline Total & 152 & 43 & 109 & & \\
\hline
\end{tabular}

Nota: Elaborado nor S. Guerra. L. Ramirez v G. Reinoso. 2016

En la Tabla 3 se muestra la identificación de las bacterias tras los análisis de las pruebas bioquímicas: si el resultado en el porcentaje de certeza es 95\% o superior quiere decir que existe una buena aproximación a la especie, caso contrario, existe una aproximación al género. Los resultados indicaron que únicamente Photobacterium damselae tuvo el $99.8 \%$ de certeza, es decir, existe gran aproximación a la especie, mientras que las otras tres cepas analizadas mostraron porcentajes inferiores al 95\%, mostrando una buena aproximación al género.

Tabla 3. Identificación de las cepas bacterianas

\begin{tabular}{ccccc}
\hline Cepas & Identificación & $\begin{array}{c}\text { Porcentaje } \\
\text { de certeza }\end{array}$ & Fotografía microscópica & $\begin{array}{c}\text { Aplicación en } \\
\text { Biorremediación }\end{array}$ \\
\hline CdM201 & Acinetobactersp & $50,70 \%$ & & $\begin{array}{c}\text { Degradan } \\
\text { hidrocarburos y } \\
\text { fracciones de } \\
\text { alcanos }\end{array}$ \\
\hline
\end{tabular}

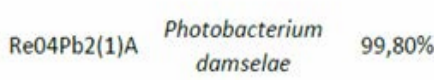
damselae

$9,80 \%$

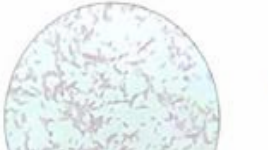

No se encontraron aplicaciones en biorremediación

LPS01Cr1

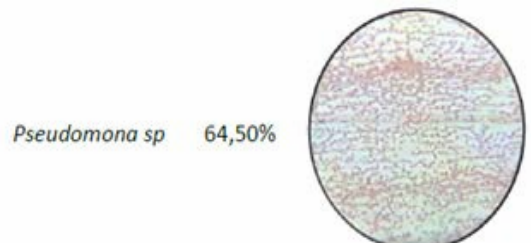

Degradan nhexadecano, hidrocarburos aromáticos y pireno y mineraliza compuestos alifáticos

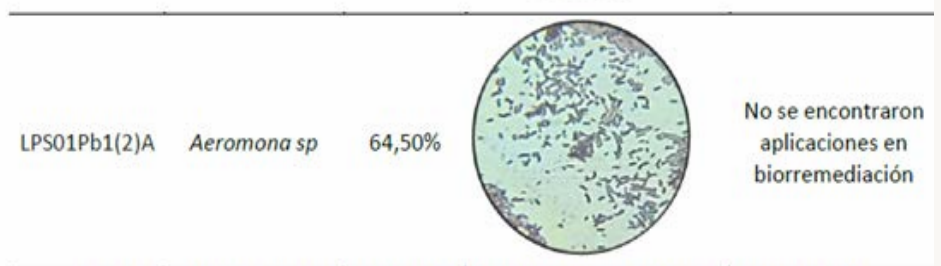

Nota: Las aplicaciones en biorremediación han sido obtenidas de la investigación: Biotransformación de metales pesados presentes en lodos ribereños de los ríos Bogotá y Tunjuelo (Soto, Gutiérrez, Rey León, \& González, 2010) y Potential of Pseudomonas sp. JH 51-2 to stabilize lead in mining site soil (Jaehong, Patrick, lk-Boo, Byung, \& Min, 2015).

\section{Análisis de la cinética de crecimiento bacteriano}

En la figura 2 se muestra las curvas de crecimiento bacteriano de las cuatro cepas experimentadas en incubación a temperatura controlada $\left(25^{\circ} \mathrm{C}\right)$ e incubación a temperatura ambiente con una concentración de 20 ppm de $\mathrm{Pb}$, en la figura 3 se muestra el crecimiento bacteriano a 100 ppm, bajo las mismas condiciones de temperatura de incubación. Al realizar un análisis comparativo entre las cuatro cepas, se determinó que Pseudomona sp presentó los valores más altos respecto a la capacidad de crecimiento a una concentración de 20 ppm a temperatura de incubación ambiente. 
Crecimiento bacteriano a 20 ppm de PbFigura 2
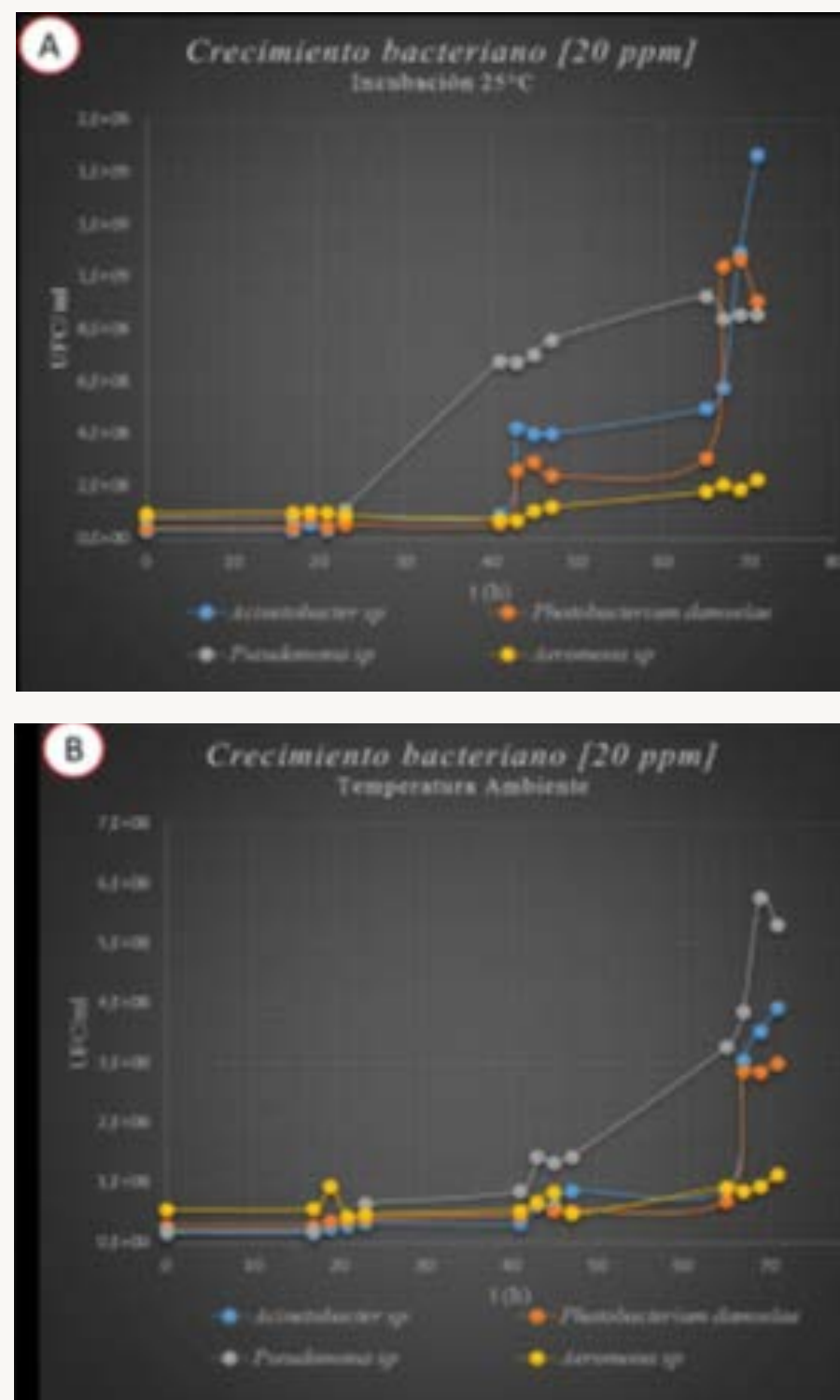

PbFigura 2. A indica el crecimiento bacteriano a 20 ppm de $\mathrm{Pb}$ en incubación a temperatura controlada de $25^{\circ} \mathrm{C}, \mathrm{B}$ indica el crecimiento bacteriano a $20 \mathrm{ppm}$ de $\mathrm{Pb}$ en incubación a temperatura ambiente. Elaborado por: S. Guerra, L. Ramírez y G. Reinoso, 2016.

\section{Crecimiento bacteriano a 100 ppm de PbFigura}

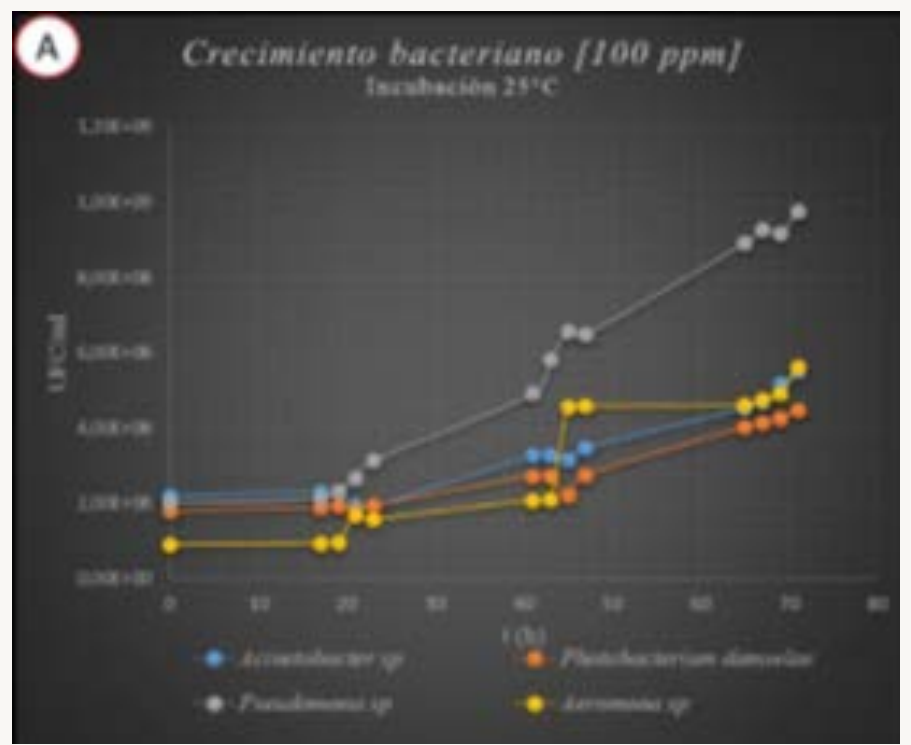

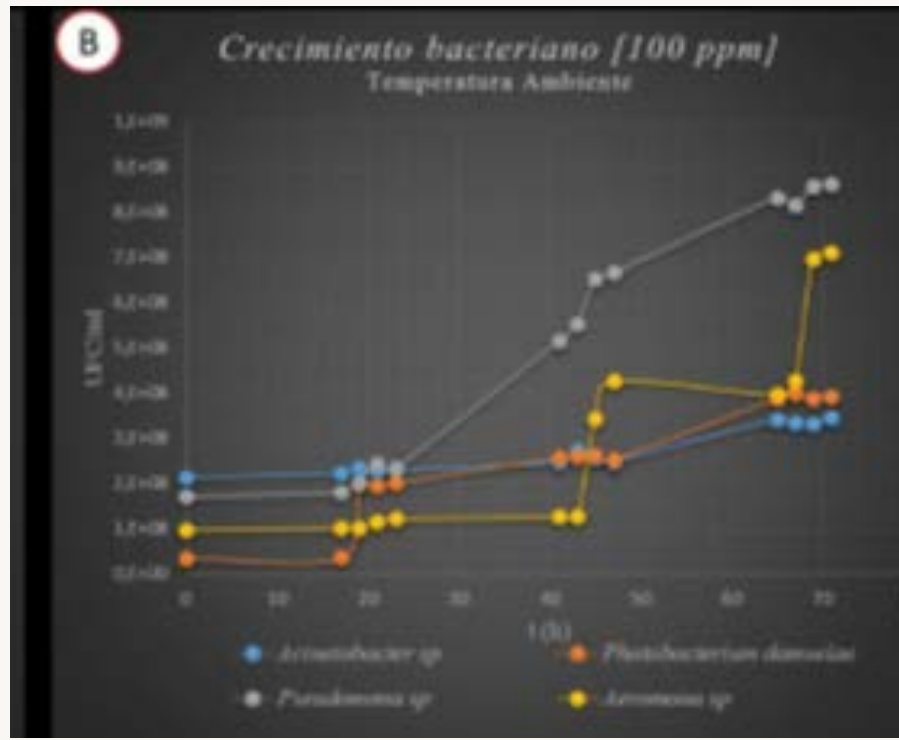

PbFigura 3. A indica el crecimiento bacteriano a 100 ppm de $\mathrm{Pb}$ en incubación a temperatura controlada de $25^{\circ} \mathrm{C}, \mathrm{B}$ indica el crecimiento bacteriano a 100 ppm de $\mathrm{Pb}$ en incubación a temperatura ambiente. Elaborado por: S. Guerra, L. Ramírez y G. Reinoso, 2016.

Como se muestra en la Tabla 4, la cepa bacteriana Pseudomona sp obtuvo la mayor velocidad de crecimiento ( $\mathrm{K}=6,60 \mathrm{E}-2)$ en un menor tiempo de generación $(\mathrm{g}=1,52 \mathrm{E}+01)$ y el segundo número de generaciones $(\mathrm{n}=$ $4,68)$ más alto, después de Acinetobacter sp. Este resultado corrobora lo expresado por Jaehong y colaboradores (2015), quienes afirman que Pseudomona sp muestra una alta tolerancia y facilidad de crecimiento a 200 ppm de Pb.

Tabla 4. Cinética de crecimiento bacteriano a 20 y 100 ppm

\begin{tabular}{|c|c|c|c|c|c|c|}
\hline \multicolumn{7}{|c|}{ Resumen de crecimiento bacteriano } \\
\hline & Cepa & & $\begin{array}{c}\text { Acinetobacter } \\
s p\end{array}$ & $\begin{array}{c}\text { Photobacterium } \\
\text { damselae }\end{array}$ & Pseudomona sp & Aeromona sp \\
\hline \multirow{6}{*}{$20 \mathrm{ppm}$} & \multirow{3}{*}{$25^{\circ} \mathrm{C}$} & K & $6,06 \mathrm{E}-02$ & $4,86 \mathrm{E}-02$ & $4,87 E-02$ & $3,29 \mathrm{E}-02$ \\
\hline & & g & $1,65 \mathrm{~F}+01$ & $2,06 E+01$ & $2,05 E+01$ & $3,04 E+01$ \\
\hline & & $n$ & & 4,37 & 3,46 & 2,99 \\
\hline & \multirow{3}{*}{ Ambiente } & K & $5,64 \mathrm{E}-02$ & $4,06 \mathrm{E}-02$ & $0 \mathrm{E}-02$ & $1,64 \mathrm{E}-02$ \\
\hline & & g & $1,77+01$ & $2,46 E+01$ & 1 1) & $6,11 E+01$ \\
\hline & & $n$ & 5,08 & 3,66 & 4,68 & 1,49 \\
\hline \multirow{6}{*}{$100 \mathrm{ppm}$} & \multirow{3}{*}{$25^{\circ} \mathrm{C}$} & K & $2,19 E-02$ & $4,78 E-02$ & $3,57 \mathrm{E}-02$ & $2,92 \mathrm{E}-02$ \\
\hline & & g & $4,57 E+01$ & $2,09 E+01$ & $2,80 E+01$ & $3,42 E+01$ \\
\hline & & $\mathrm{n}$ & 1,95 & 4,25 & 2,53 & 2,66 \\
\hline & \multirow{3}{*}{ Ambiente } & K & $1,55 \mathrm{E}-02$ & $4,71 \mathrm{E}-02$ & $2,29 \mathrm{E}-02$ & $3,17 \mathrm{E}-02$ \\
\hline & & g & $6,46 E+01$ & $2,13 E+01$ & $4,37 E+01$ & $3,16 E+01$ \\
\hline & & $\mathrm{n}$ & 1,38 & 4,19 & 1,63 & 2,88 \\
\hline
\end{tabular}

Nota: Los círculos en azul indican los valores máximos del número de generaciones (n), la mayor velocidad de crecimiento $(k)$ y el tiempo de generación más bajo $(\mathrm{g})$. Flahorado nor. S Guerra I Ramírez u G Rainoen 2016

En la Figura 4 se muestra las curvas de remoción de $\mathrm{Pb}$ de las cepas experimentadas en incubación a temperatura controlada $\left(25^{\circ} \mathrm{C}\right)$ e incubación a temperatura ambiente con una concentración de 20 ppm de Pb, del mismo modo en la Figura 5 se muestra la remoción de $\mathrm{Pb}$ a 100 ppm bajo las mismas condiciones de temperatura de incubación. 
Remoción de Plomo a 20 ppm
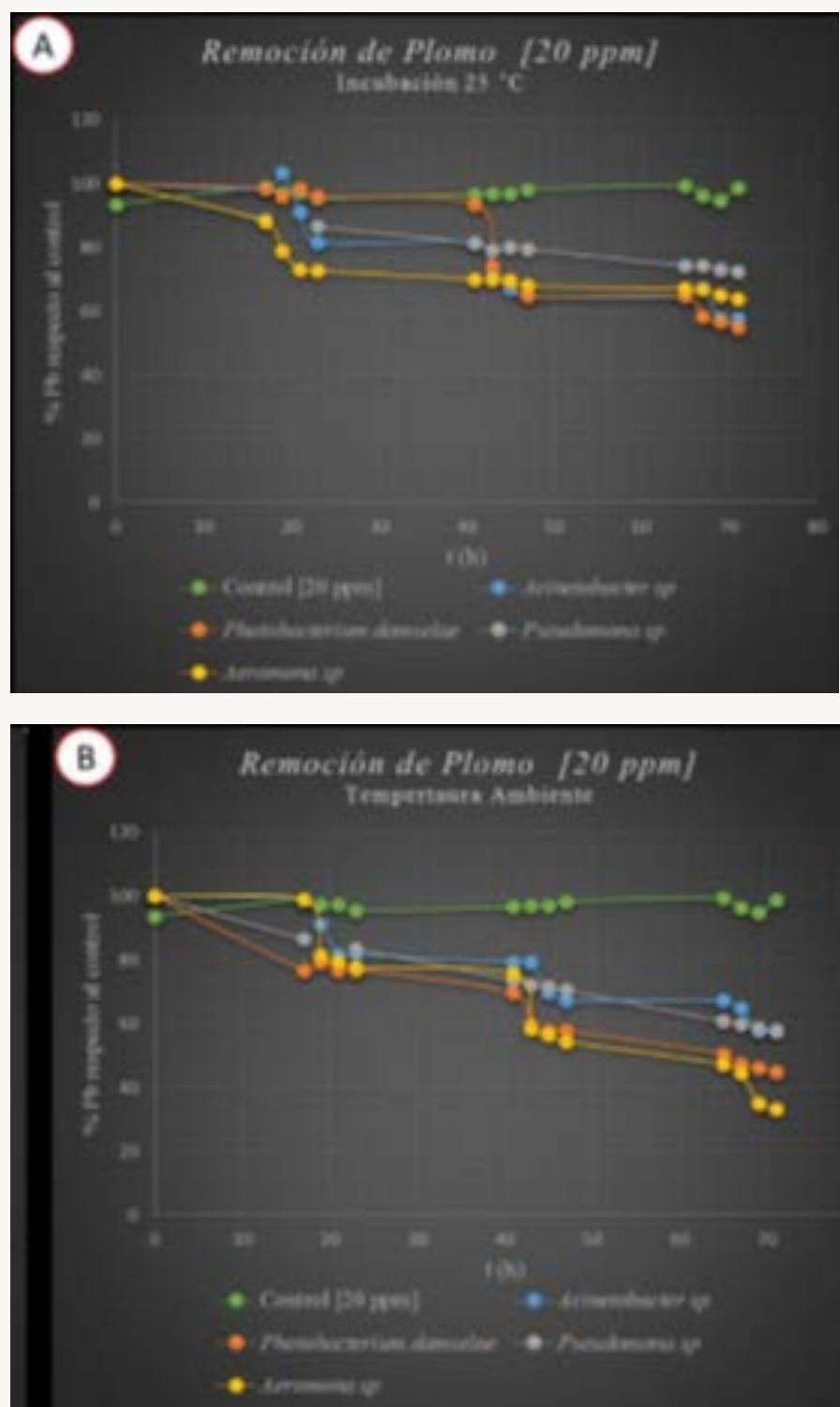

Figura 4. A indica la remoción de $\mathrm{Pb}$ a 20 ppm en incubación a temperatura controlada de $25^{\circ} \mathrm{C}, \mathrm{B}$ indica la remoción de $\mathrm{Pb}$ a 20 ppm en incubación a temperatura ambiente.

Elaborado por: S. Guerra, L. Ramírez y G. Reinoso, 2016

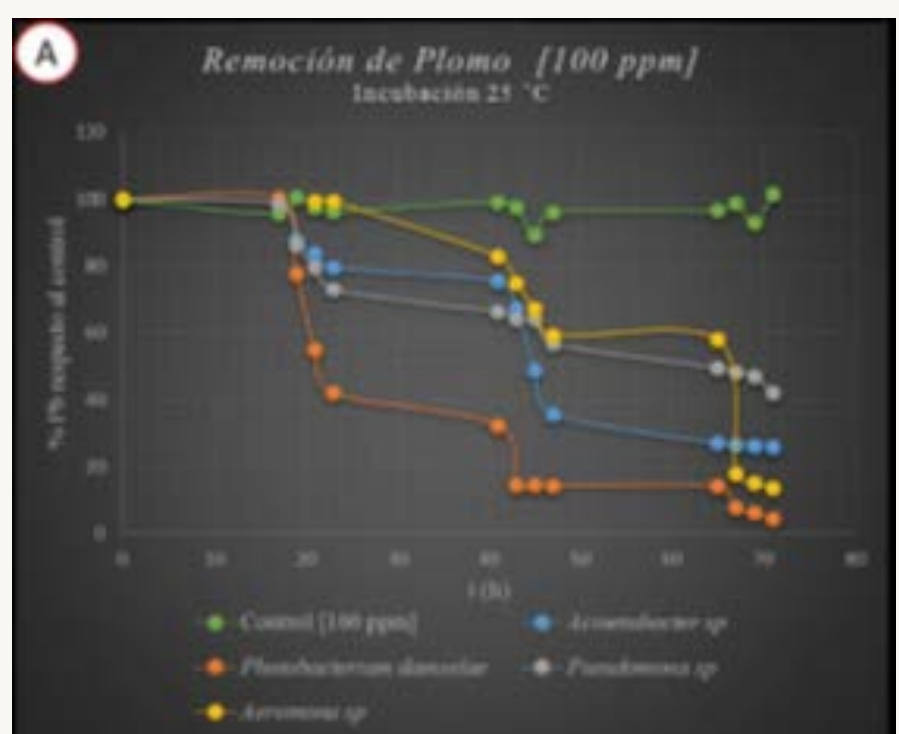

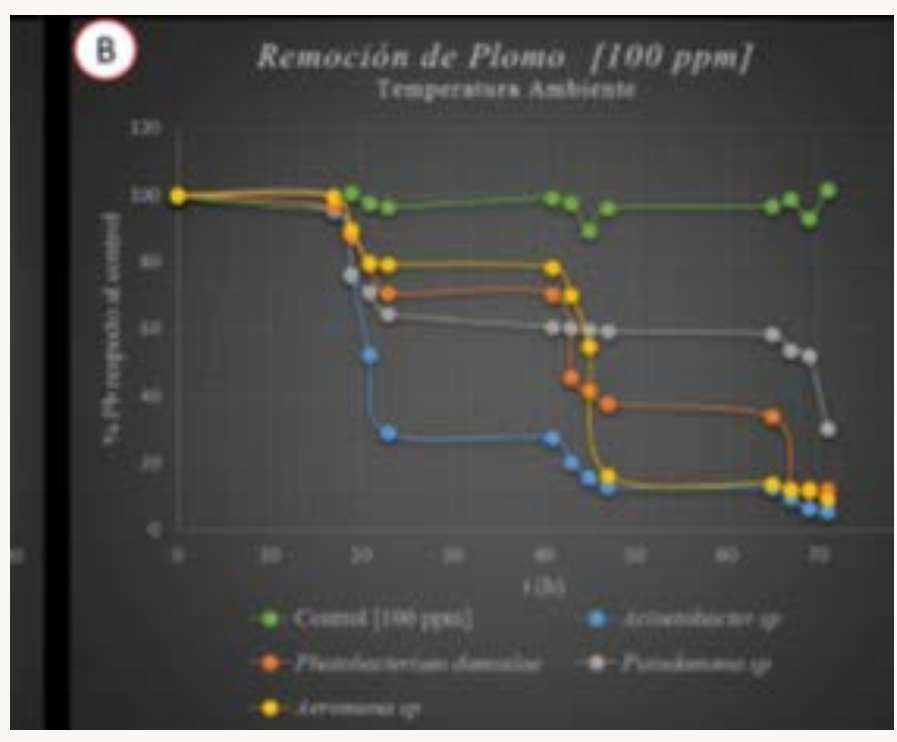

Remoción de Plomo a 100 ppmFigura 5.

ppmFigura 5. A indica la remoción de $\mathrm{Pb}$ a 20 ppm en incubación a temperatura controlada de $25^{\circ} \mathrm{C}, \mathrm{B}$ indica la remoción de $\mathrm{Pb}$ a 20 ppm en incubación a temperatura ambiente.

Elaborado por: S. Guerra, L. Ramírez y G. Reinoso, 2016

Tabla 5. Capacidad de remoción de Pb a 20 y 100 ppm

\begin{tabular}{|c|c|c|c|c|c|c|c|c|}
\hline \multirow{4}{*}{ Cepa } & \multicolumn{7}{|c|}{ Resumen de remoción de $\mathrm{Pb}$} & \\
\hline & \multicolumn{4}{|c|}{$20 \mathrm{ppm}$} & \multicolumn{4}{|c|}{$100 \mathrm{ppm}$} \\
\hline & \multicolumn{2}{|c|}{ \% Remoción } & \multicolumn{2}{|c|}{ Concentración } & \multicolumn{2}{|c|}{ \% Remoción } & \multicolumn{2}{|c|}{ Concentración } \\
\hline & $25^{\circ} \mathrm{C}$ & $\begin{array}{c}\text { Ambien } \\
\text { te }\end{array}$ & $25^{\circ} \mathrm{C}$ & $\begin{array}{c}\text { Ambien } \\
\text { te }\end{array}$ & $25^{\circ} \mathrm{C}$ & $\begin{array}{c}\text { Ambien } \\
\text { te }\end{array}$ & $25^{\circ} \mathrm{C}$ & $\begin{array}{c}\text { Ambien } \\
\text { te }\end{array}$ \\
\hline $\begin{array}{l}\text { Acinetobacter } \\
s p\end{array}$ & $42,40 \%$ & $41,90 \%$ & 12,00 & 12,10 & $74,09 \%$ & $94,57 \%$ & 26,45 & 5,54 \\
\hline $\begin{array}{l}\text { Photobacterium } \\
\text { damselae }\end{array}$ & $44,90 \%$ & $88,50 \%$ & 44,80 & 32 & $95,45 \%$ & $87,82 \%$ & 4,65 & 12 \\
\hline Pseudomona sp & $52,00 \%$ & $52,00 \%$ & 10,00 & 10,00 & $44,4 / \%$ & $90,30 \%$ & 56,70 & 4,05 \\
\hline Aeromonasp & $35,00 \%$ & $64,90 \%$ & 13,50 & 7,31 & $86,29 \%$ & $88,29 \%$ & 14,00 & 11,96 \\
\hline
\end{tabular}

Nota: El circulo en amarillo muestra el mayor porcentaje de remoción de las cinco bacterias

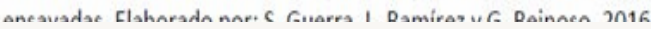

Los resultados obtenidos al evaluar la capacidad bacteriana de remoción, mostrados en la Tabla 5, indicaron que Pseudomona sp presentó el porcentaje de remoción de $\mathrm{Pb}$ más alto (96.30\%) a 100 ppm e incubación a temperatura ambiente. En su estudio Jaehong y colaboradores (2015), determinaron que las bacterias del género Pseudomona sp lograron remover hasta un $87 \%$ de $\mathrm{Pb}$ a una concentración de 100 ppm, y además mostró una tolerancia de hasta 400 ppm alcanzando un $61 \%$ de remoción. Con los resultados precedentes se pudo comprobar lo mencionado por Torres (2003), quien afirma que: el género Pseudomona es considerado como una de las bacterias más eficientes en la degradación de compuestos tóxicos y la remoción de metales pesados. 
El valor más alto de remoción de Pb para el caso de Pseudomona sp se obtuvo en un rango de pH que varió de fuertemente ácido a ligeramente ácido $(4,2-6,1)$, el mismo que fue registrado a 100 ppm en incubación a temperatura ambiente que varió de 18 a $23{ }^{\circ} \mathrm{C}$; esto concuerda con los resultados obtenidos en su estudio por Tur y colaboradores (2013), quienes lograron determinar que el mayor porcentaje eficiencia de remoción de $\mathrm{Pb}$ fue del 97,4\% a pH 5,2 a una temperatura ambiente de $32^{\circ} \mathrm{C}$.

\section{Conclusiones}

De acuerdo con los resultados obtenidos en esta investigación, se analizó un total de 152 colonias bacterianas, en la fase de aislamiento y bioestimulación; se seleccionaron 12 cepas morfológicamente diferentes, de las cuales seis cepas lograron adaptarse al medio de cultivo con $\mathrm{Pb}$, presentando resistencia y/o tolerancia a las diferentes concentraciones experimentadas.

En los resultados de las pruebas bioquímicas del Kit Microgen GN-IDA+B para la identificación de bacterias resistentes al Pb, se pudo identificar los géneros: Acinetobacter, Pseudomona, Aeromona y la especie Photobacterium damselae, que obtuvo el 99,8\% de certeza, es decir, que presenta una gran aproximación a la especie, mientras que las otras tres cepas analizadas muestran una buena aproximación al género.

En el análisis de la cinética de crecimiento bacteriano se determinó que Pseudomona sp presentó una mayor facilidad de crecimiento a una concentración de 20 ppm, a temperatura de incubación ambiente, debido a su mayor velocidad de crecimiento en un tiempo de generación menor.

En el análisis de la curva de remoción de $\mathrm{Pb}$, Pseudomona sp registró un porcentaje de remoción del 96,30\% a una concentración de 100 ppm e incubación a temperatura ambiente, siendo este valor el más alto de las cuatro cepas experimentadas, es por esta razón que este género ha sido considerado como uno de los más eficientes en la degradación de compuestos tóxicos y metales pesados.

\section{Referencias bibliográficas}

Ambuludi, A. \& Hoyos, A. (2013). Necesidad de reformar el Art. 11 de la Ley de Prevención y Control de la Contaminación Ambiental acerca de la responsabilidad por daños ambientales. Universidad Nacional de Loja. Recuperado de http://dspace.unl.edu.ec/jspui/ bitstream/123456789/808/1/TESISFINAL.pdf
Bustos, A. \& Garzón, K. (2015). Aplicación de Indicadores de Gestión Ambiental para medir la contaminación por emisiones a la atmósfera y residuos sólidos generados por las empresas del sector de la industria metalúrgica en el $D M Q$ en el periodo 2012-2013. Universidad Politécnica Salesiana. Recuperado de http://dspace.ups.edu.ecl bitstream/123456789/9814/1/QT07773.pdf

Castillo, L. \& Barragán, B. (2011). Aplicaciones biotecnológicas de microorganismos halófilos. Revista Sistemas Ambientales, 4(2), 45-54. Recuperado de http://servicios.encb.ipn.mx/revistaisa/Vol.4No.2/

AplicacionesBiotecnológicasdeMicroorganismosHalófilos.p df

Eróstegui Revilla, C. P. (2009). Contaminación por metales pesados. Revista científica Ciencia Médica, 12(1), 45-46.

García, J., Castells, X. E. \& Gaya, J. (2012). Impactos Ambientales y Energía (Días de Sa). Madrid.

González, E. (2011). Concepto y estrategias de biorremediación, 20-29. Recuperado de http:/l csifesvr.uan.edu.co/index.php/ingeuan/article/ download/96/PDF

Greenpeace. (2008). Informe de Contaminación en España. Barcelona. Recuperado de http:/l www.greenpeace.org/espana/Global/espana/report/ contaminacion/contaminacin-en-espa-a.pdf

Guevara, M. F. \& Ramírez, L. J. (2015). Eichhornia crassipes, su invasividad y potencial fitorremediador. Revista de Ciencias de La Vida: La Granja, 22(2), 5-11. Recuperado de http://doi.org/10.17163/lgr.n22.2015.01

Jaehong, S., Patrick, J. S., Ik-Boo, J., Byung, T. O., \& Min, C. (2015). Potential of Pseudomonas sp. JH 51-2 to stabilize lead in mining site soil, 36(May), 537-542.

Morales, B. (2012). Microorganismos en la Industria.

Ramírez, J. C., Ulloa, P., Velázquez, M., Ulloa, J., \& Arce, F. (2011). Bacterias lácticas: Importancia en alimentos y sus efectos en la salud. Revista Fuente, Año 2(7), $16 . \quad$ Recuperado de http:/l www.hablemosclaro.org/repositorio/biblioteca/

b_305_bacterias_lacticas_importancia_en_alimentos.pdf

Ramírez, L. \& Coba, P. (2012). Aislamiento, caracterización y conservación de bacterias no entéricas con capacidad de adaptación en altas concentraciones de plata, presentes en una laguna de sedimentación de la planta minera del sector el Pache-Portovelo-El Oro. Universidad Politécnica Salesiana. Recuperado de http:// dspace.ups.edu.ec/bitstream/123456789/6630/1/UPSQT04656.pdf

Safont, B. (2012). Biodegradación de fenol en un reactor en régimen de spouted bed con partículas de ßciclodextrina, 362. 
Sánchez, J, \& Rodríguez, J. (2010). Fundamentos y Aspectos Microbiológicos: Biorremediación. Universidad de Oviedo, 1, 12-16.

Soto, C., Gutiérrez, S., Rey León, A., \& González, E. (2010). Biotransformación de metales pesados presentes en lodos ribereños de los ríos Bogotá y Tunjuelo. Nova, 195-205. Recuperado de http:// www.unicolmayor.edu.co/invest_nova/NOVA/ NOVA14_ARTORIG6.pdf

Suárez, P. \& Reyes, R. (2002). La incorporación de metales pesados en las bacterias y su importancia para el ambiente. Interciencia, 27, 160 - 164. Recuperado de http://www.redalyc.org/articulo.oa?id=33906702

Torres, D. (2003). El papel de los microorganismos en la biodegradación de compuestos tóxicos. Ecosistemas Revista científica y técnica de Ecología y Medio Ambiente, XII (2), 1-5. Recuperado de http:// www.redalyc.org/pdf/540/54012219.pdf

Turcios, J. \& García, G. (2010). Determinación cuantitativa de arsénico, cobre, plomo y cadmio en (Brasica oleracea) brócoli que se cultiva en la parcela de San José. Facultad de Ciencias Químicas y Farmacia. Universidad de San Carlos de Guatemala, Guatemala. Recuperado de http://

biblioteca.usac.edu.gt/tesis/06/06_2876.pdf

Tur, E., Orbera, T., Álvarez, Y., \& Pérez, R. (2013). Bioadsorción de plomo (II) por biomasa microbiana seca: Efectos del pH. Revista Cubana de Química, XXV (II), 75-81. Recuperado de https:// www.researchgate.net/.../278028590_Bioadsorcion_de_ plomo_II_p...

Volke, T. (2002). Biorremediación de suelos contaminados. Centro Nacional De Investigación $Y$ Capacitación Ambiental, 25-39. Recuperado de http:// www.smbb.com.mx/revista/Revista_2002_1/ biorremediacion.pdf 